\title{
Prediction of Violent Behaviour in Psychiatryc Emergency Room
}

\author{
Lefter Sinani ${ }^{1}$, Fabian Cenko ${ }^{2}$ \\ ${ }^{1}$ Psychiatric Hospital, University Hospital Centre “Mother Teresa”, Tirana, Albania. \\ ${ }^{2}$ Faculty of Medicine, Tirana, Albania
}

\begin{abstract}
The highest incidence of workplace violence occurs in psychiatric wards, emergency departments (EDs), waiting rooms, and geriatric units (). The aim was to identify risk and protective factors of violent behaviours and to establish the criterion to which the HCR-20 predicts the verbal, physical and property violence. This is a prospective cohort study including 217 patients. Psychiatric evaluation to patients admited in emergency ward of psychiatric hospital at UHC "Mother Tereza" over the period 2011 - 2014, was done based on structural clinical interviews and questionnaires related to violent behaviors and risk factors. HCR scoring criterion for the classification of patients in violent and non-violent is $>21$ for verbal violence and property (fig. 2) and $>27$ for physical violence (fig. 3). It was found that the sensitivity of each curve of the type of violence to classify patients in violent and non-violent is very high, $>85 \%$. The successful management of violence is predicated on an understanding of its dynamics.
\end{abstract}

Keywords: violent behaviour, psychiatric disorder, HCR, incidents

\section{Introduction}

The highest incidence of workplace violence occurs in psychiatric wards, emergency departments (EDs), waiting rooms, and geriatric units $(1,2)$. The ED is recognized as an area at special risk of violence. The 24-hour accessibility, lack of adequately trained, armed, or visible security guards, and a highly stressful environment are some of reasons why EDs are vulnerable to violence $(3,4)$. The overwhelming majority of perpetrators of ED violence are patients, their family members and visitors $(5,6)$. The unanticipated nature of illness such as acute illness and trauma, patient pain and discomfort, as well as the tension, stress, and anger of patients and their relatives, and adverse unexpected outcomes such as death are often compounded by cramped space, lack of privacy and intense interpersonal interactions (7), and long waiting times for consultation or admission. Assessment of the risk of violence by patients is expected of all clinicians who have a relationship with a patient for evaluation or treatment: psychiatrists, other physicians, psychologists, nurses, social workers, activity therapists, and all other staff members who have responsibilities for patients. The responsibility to assess the Risk of violence exists when clinicians evaluate a patient in the emergency department and decide whether to discharge or admit; see a patient in an office setting for the first time and between outpatient visits; admit a patient to a hospital and order a level of observation; and provide other immediate treatment as the patient enters the hospital $(8,9)$ It exists during inhospital diagnosis and treatment, including monitoring the patient and deciding whether seclusion or restraint should be used. It exists in the decision to discharge the patient and in the planning and implementation of care after discharge. A number of researchers have reviewed many instruments that assess the risk of violence by using actuarial methods. They found that greater integration of clinical, dynamic data more relevant to general adult psychiatry is needed in the assessment of the short-term risk of violence. The model presented in this section describes at least 10 factors that must be evaluated in determining whether a patient poses a short-term risk of violence $(10,11)$. These factors are not scored to produce a global numerical indication of risk, such as 6 out of 10 indicating risk but 4 out of 10 not indicating risk of short-term violence. Rather, information obtained in each area should be synthesized and weighed by the evaluator to form a clinical decision about short-term risk of violence.

The clinician must keep in mind that some factors may be more important than others for the individual patient, such as a history of violence with alcohol use or accompanying noncompliance with medication or other aspects of treatment. Even after making a decision about the patient's risk of violence, the clinician must keep in mind that unexpected events can still occur that may provoke violence, such as resumption of alcohol or drug use or a patient's spouse asking for a divorce (table 1). The aim was to identify risk and protective factors of violent behaviours and to establish the criterion to which the HCR-20 predicts the verbal, physical and property violence $(12,13)$

\section{Material and Method}

This is a prospective cohort study including 217 patients. Psychiatric evaluation to patients admited in emergency ward of psychiatric hospital at UHC "Mother Tereza" over the period 2011 - 2014, was done based on structural clinical interviews and questionnaires related to violent behaviors and risk factors. Participants were assessed with the HCR-20 test upon admission to the EW. The frequency and severity of violent incidents during the follow-up in EW were measured by application of MOAS test. Further quality information regarding violent incidents was collected through staff interviews. Statistical analyses of the study database were done with SPSS package version 16.

\section{Results and Discussion}

Violence is a heterogeneous group of behaviors, and risk factors differ for different types of violence. Second, not 


\section{International Journal of Science and Research (IJSR) \\ ISSN (Online): 2319-7064}

Index Copernicus Value (2013): 6.14 | Impact Factor (2015): 6.391

only are there numerous risk factors in different domains, but given the dynamic nature of development, different risk factors become salient at different ages. One hundreed thirty four patients $(45 \%)$ reported at least one act of verbal violence, 50 patients $(17 \%)$ committed at least one act of physical violence and and 114 patients $(38 \%)$ committed violoence against property (14).

In multivariate analysis noted that total HCR $(p<0.01)$, history of violence $(\mathrm{p}<0.01)$ and the higher status of management $(\mathrm{p}=0.04)$ are significant independent risk factors for current violence. HCR scoring criterion for the classification of patients in violent and non-violent is $>21$ for verbal violence and property (fig. 2) and $>27$ for physical violence (fig. 3). It was found that the sensitivity of each curve of the type of violence to classify patients in violent and non-violent is very high, $>85 \%$. In multivariate linear regression analysis connection of the number of incidents of HCR ladders, it was noted that HCR total ( $p=$ $0: 01)$ and $\mathrm{H} 1(\mathrm{p}=0: 01)$ are significant predictors of violence (15). No statistically significant difference was found on total HCR score according groups of diagnoses $($ ANOVA F-ratio $=1: 19 \mathrm{p}=0.3)$

\section{Conclusions}

The successful management of violence is predicated on an understanding of its dynamics. Violence is a reaction to feelings of passivity and helplessness. A patient's threatening behavior is commonly an overreaction to feelings of impotence, helplessness, and perceived or actual feelings of humiliation. A clinician who encounters a threatening patient should avoid becoming verbally or physically aggressive toward the patient. Psychiatrists who respond to threatening patients with physical or verbal aggression are significantly more likely to be injured or have property destroyed than those who acknowledge their fear but also express a desire to help the patient. The strategy of a nonthreatening offer to provide help is reassuring to the patient and is the centerpiece for intervention with a potentially violent patient.

\section{References}

[1] Arnetz J, Hamblin L, Essenmacher L, Upfal M, Ager J, Luborsky, M. Understanding patient-to-worker violence in hospitals: a qualitative analysis of documented incident reports. J Adv Nurs. 2014. [PubMed]

[2] Nolan P, Dallender J, Soares J, Thomsen S, Arnetz B. Violence in mental health care: the experiences of mental health nurses and psychiatrists. J Adv Nurs. 1999;30:934-41. doi: 10.1046/j.13652648.1999.01163.x. [PubMed] [Cross Ref]

[3] Hesketh K, Duncan S, Estabrooks C, Reimer M, Giovannetti P, Hyndman K, et al. Workplace violence in Alberta and British Columbia hospitals. Health Policy. 2003;63:311-21. doi: 10.1016/S01688510(02)00142-2. [PubMed] [Cross Ref]

[4] Registered Nurses' Association of Ontario . Best practice guideline: Preventing and managing violence in the workplace. Toronto: Registered Nurses Association of Ontario; 2009.

[5] Jonker E, Goossens P, Steenhuis I, Oud N. Patient aggression in clinical psychiatry: Perceptions of mental

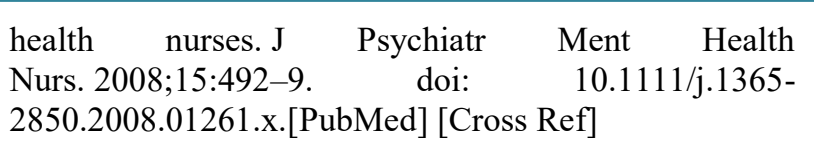

[6] Campbell J, Messing J, Kub J, Agnew J, Fitzgerald S, Fowler B, et al. Workplace violence: Prevalence and risk factors in the safe at work study. Journal of Occupational Health and Environmental Medicine.2011;53:82-9. doi: 10.1097/JOM.0b013e3182028d55. [PubMed] [Cross Ref]

[7] Moylan L, Cullinan M. Frequency of assaults and severity of injury of psychiatric nurses in relation to the nurses' decision to restrain. J Psychiatr Ment Health Nurs. 2011;18:526-34. doi: 10.1111/j.13652850.2011.01699.x. [PubMed] [Cross Ref]

[8] Gates D, Gillespie G, Succop P. Violence against nurses and its impact on stress and productivity. Nurs Econ. 2011;29:59-66.9. [PubMed]

[9] Shields M, Wilkins K. Findings from the 2005 National Survey of the Work and Health of Nurses.Canadian Institute for Health Information: Ottawa; 2006.

[10] Sofield L, Salmond S. Workplace violence: A focus on verbal abuse and intent to leave the organization.Orthop Nurs. 2003;22:274-83. doi: 10.1097/00006416200307000-00008. [PubMed] [Cross Ref]

[11] Chen C, Huang C, Hwang J, Chen C. The relationship of health-related quality of life to workplace physical violence against nurses by psychiatric patients. Qual Life Res. 2010;19:1155-61. doi: 10.1007/s11136-0109679-4. [PubMed] [Cross Ref]

[12] Pai H, Lee S. Risk factors for workplace violence in clinical registered nurses in Taiwan. J Clin Nurs.2011;20:1405-12. doi: 10.1111/j.13652702.2010.03650.x. [PubMed] [Cross Ref]

[13] Owen C, Tarantello C, Jones M. Violence and aggression in psychiatric units. Psychiatr Serv.1998;49:1452-7.

doi: 10.1176/ps.49.11.1452. [PubMed] [Cross Ref]

[14]Kisa S. Turkish nurses' experience of verbal abuse at work. Arch Psychiatr Nurs. 2008;22:200-7. doi: 10.1016/j.apnu.2007.06.013. [PubMed] [Cross Ref]

[15]Roche M, Diers D, Duffield C, Catling-Paull C. Violence toward nurses, the work environment and patient outcomes. J Nurs Scholarsh. 2009;42:13-22. doi:

$10.1111 / \mathrm{j} .1547-$ 5069.2009.01321.x. [PubMed][Cross Ref]

Table 1: Factors that must be evaluated in the assessment of short-term risk of violence

\begin{tabular}{|l|}
\hline Factors \\
\hline 1. Appearance of the patient \\
\hline $\begin{array}{l}\text { 2. Presence of violent ideation and degree of formulation } \\
\text { and/or planning }\end{array}$ \\
\hline 3. Intent to be violent \\
\hline 4. Available means to harm and access to the potential victim \\
\hline 5. Past history of violence and other impulsive behaviors \\
\hline 6. Alcohol or drug use \\
\hline 7. Presence of psychosis \\
\hline 8. Presence of certain personality disorders \\
\hline 9. History of noncompliance with treatment \\
\hline 10. Demographic and socioeconomic characteristics \\
\hline
\end{tabular}




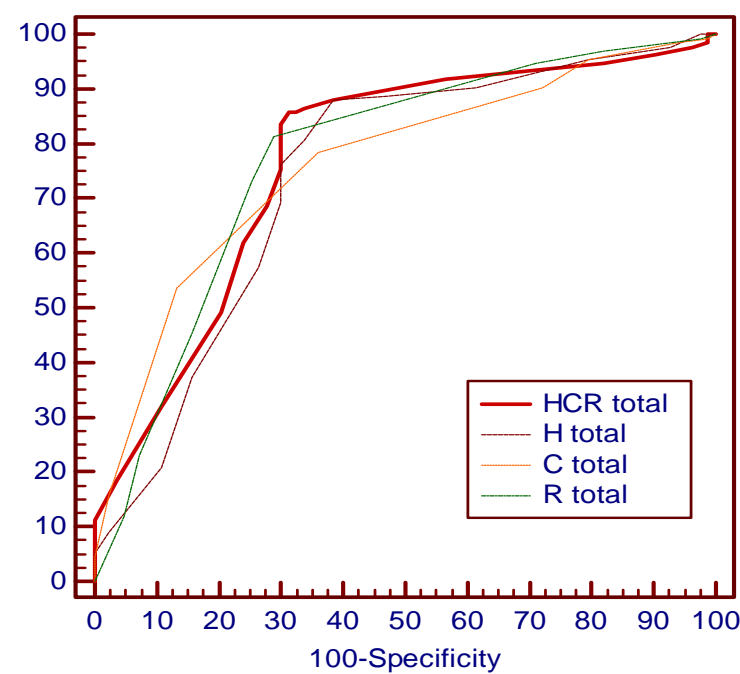

Figure 1: ROC curve of HCR-20 for prediction of violence

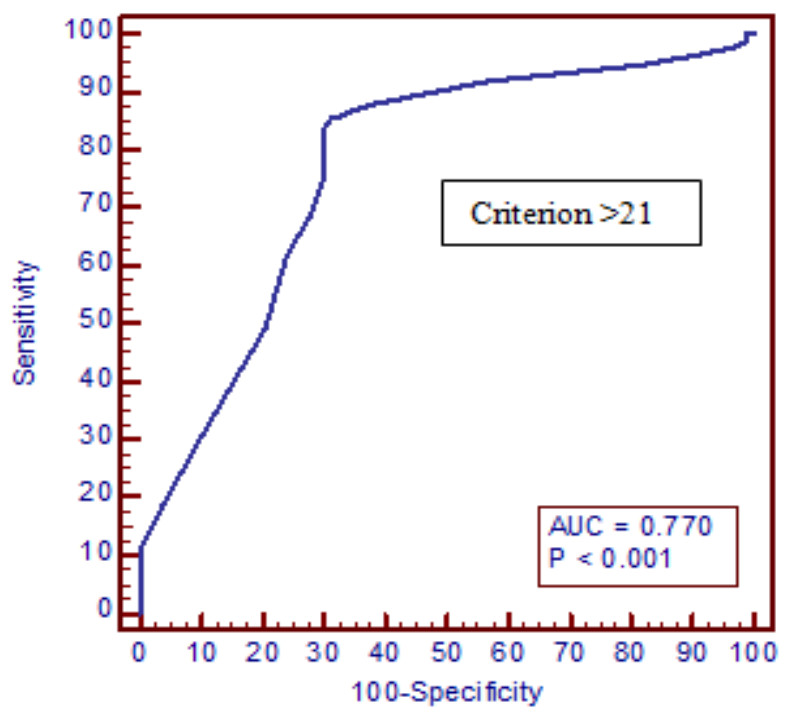

Figure 2: ROC curve of HCR-20 for prediction of verbal and property violence

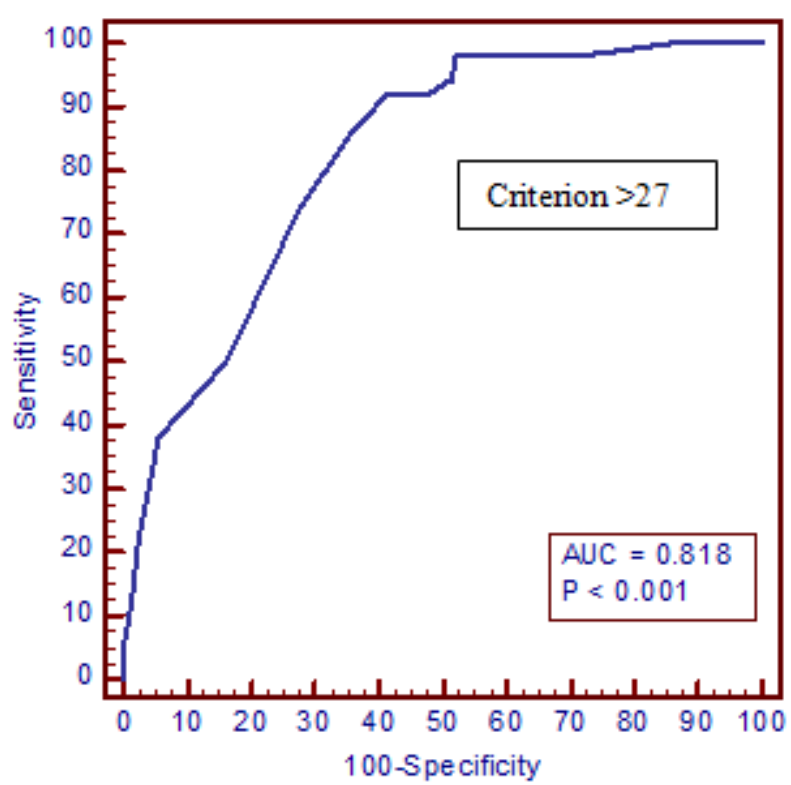

Figure 2: ROC curve of HCR-20 for prediction of physical violence

Volume 5 Issue 7, July 2016 www.ijsr.net

Licensed Under Creative Commons Attribution CC BY 